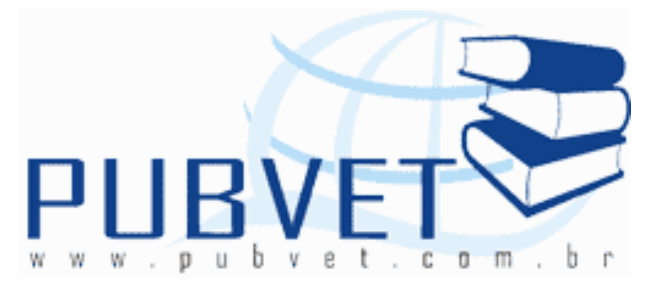

PUBVET, Publicações em Medicina Veterinária e Zootecnia.

\title{
Produção de leite com vacas mestiças em capim-elefante ${ }^{1}$
}

João Avelar Magalhães², Braz Henrique Nunes Rodrigues³, Raimundo Bezerra de Araújo Neto ${ }^{4}$, Newton de Lucena Costa ${ }^{5}$, Eduardo Esmeraldo Augusto Bezerra $^{6}$, José Miguel dos Santos ${ }^{7}$, Roberto Cláudio Fernandes Franco Pompeu ${ }^{8}$

${ }^{1}$ Pesquisa financiada pelo FUNDECI/Banco do Nordeste

2 Méd.Vet., D.Sc., Pesquisador da Embrapa Meio-Norte. Parnaíba, PI.

${ }^{3}$ Eng. Agrícola, D.Sc. Pesquisador da Embrapa Meio-Norte

${ }^{4}$ Eng. Agr., M.Sc., Pesquisador da Embrapa Meio-Norte.

5 Eng. Agr., M.Sc., Pesquisador da Embrapa Roraima. Doutorando em Agronomia/Produção Vegetal, UFPR, Curitiba, PR.

${ }^{6}$ Méd.Vet., M.Sc., Emater-PI/UESPI. Parnaíba, PI.

${ }^{7}$ Contabilista, B.Sc., Analista de Pesquisa da Embrapa Meio-Norte.

${ }^{8}$ Eng. Agr., D.Sc., Pesquisador da Embrapa Caprinos

\section{Resumo}

Este trabalho teve por objetivo identificar fontes econômicas de suplementação alimentar para vacas leiteiras em regime exclusivo de pastagem de capimelefante (Pennisetum purpureum cv. Napier), submetido à adubação e à irrigação. O delineamento experimental utilizado foi inteiramente casualizado com três tratamentos: $\mathrm{T} 1$ = vacas em lactação mantidas exclusivamente em pastagem de capim-elefante; $\mathrm{T} 2=\mathrm{T} 1+$ banco de proteína de leucena e $\mathrm{T} 3=$ T1 + ração concentrada, fornecida na quantidade de $1 \mathrm{~kg}$ para cada $3 \mathrm{~kg}$ de 
MAGALHÃES, J.A. et al. Produção de leite com vacas mestiças em capim-elefante. PUBVET, Londrina, V. 5, N. 35, Ed. 182, Art. 1226, 2011.

leite produzido acima de $5 \mathrm{~kg}$. A maior produção leiteira foi obtida dos animais do T3 (11,11 kg de leite/vaca/dia e $3.594,08 \mathrm{~kg}$ de leite/vaca/lactação), seguida do T2 (9,19 kg de leite/vaca/dia e 2.740,15 de leite/vaca/lactação) e T1 (8,54 kg de leite/vaca/dia e $2.520,36 \mathrm{~kg}$ de leite/vaca/lactação). A menor rentabilidade foi obtida com vacas em pastagem de capim-elefante suplementada com concentrados.

Termo para indexação: custos, pastagem, Pennisetum purpureum

\title{
Production of milk with crossbred dairy cows in elephant-grass pastures
}

\begin{abstract}
A trial was carried out with objective of identifying economical sources of alimentary supplementation for cows milk in exclusive feeding regime of elephant-grass pasture (Pennisetum purpureum cv. Napier), submitted to the fertilization and irrigation. The experimental design was completely randomized with three treatments: $\mathrm{T} 1=$ cows grazing exclusively in elephant-grass pasture; $\mathrm{T} 2=\mathrm{T} 1+$ bank of leucena protein and $\mathrm{T} 3=\mathrm{T} 1+$ concentrated ration, supplied in the amount of $1 \mathrm{~kg}$ for each $3 \mathrm{~kg}$ of milk produced above 5 $\mathrm{kg}$. The largest production milk was obtained of the animals of T3 (11.11 kg of milk/cow/day and 3,594.08 kg of milk/cow/lactation), followed by T2 (9.19 kg of milk/cow/day and $2,740.15 \mathrm{~kg}$ of milk/cow/lactation) and T1 (8.54 milk/cow/day $\mathrm{kg}$ and 2,520.36 milk/cow/lactation $\mathrm{kg}$ ). The lower profitability was obtained with cows grazing elephant-grass supplemented with concentrates.
\end{abstract}

Index terms: costs, grassland, Pennisetum purpureum

\section{Introdução}

A alternativa racional para melhoria na competitividade e sustentabilidade da produção de leite no Brasil é a saída do sistema estabulado de gado puro ou de elevada mestiçagem da raça holandesa para o sistema de 
MAGALHÃES, J.A. et al. Produção de leite com vacas mestiças em capim-elefante. PUBVET, Londrina, V. 5, N. 35, Ed. 182, Art. 1226, 2011.

produção intensiva em pastagens adubadas e irrigadas. Esses sistemas de produção de leite são mais competitivos, considerando-se os baixos investimentos em instalações e equipamentos, quando comparados com os sistemas de confinamento e geralmente têm menores custos de mão-de-obra e alimentação. Todavia, nas condições tropicais, a competitividade e a sustentabilidade da produção de leite em pastagem dependem da escolha correta da forrageira, do tipo de animal utilizado e do grau de conhecimento das interações pasto $x$ animal, traduzido pelo esquema de manejo recomendado.

Um fator que restringe a produção intensiva e sustentável de leite exclusivamente a pasto é a estacionalidade da produção de forragem. Entretanto, o uso da irrigação das pastagens elimina ou reduz os efeitos da produção de forragem estacional, decorrentes das secas ou estiagens. CaroCostas e Vicente-Chandler (1969) reportaram que os primeiros 10 litros de leite produzidos por uma vaca podem ser alcançados em regime de pastejo, com o uso de forrageiras tropicais. No entanto, para maximizar a produção de leite em determinados estágios de lactação ou, para obter produções diárias de indivíduos com potencial leiteiro acima deste valor, é necessário o aporte suplementar de proteína e energia. Administrar ração concentrada a vacas leiteiras é uma prática bastante eficiente do ponto de vista nutricional, porém, onera de forma considerável os custos de produção.

Ultimamente, existe grande demanda por informações sobre o uso do capim-elefante (Pennisetum purpureum) em sistema de lotação rotativa para produção de leite, visando, principalmente, à diminuição dos custos de produção (DEREZ, 2001). Segundo Lima et al. (2006), vacas mantidas em pastos de capim-elefante, submetidos à lotação rotacionada, podem produzir de 8 a 14kg de leite/dia. Na região semi-árida de Minas Gerais, esta gramínea, irrigada e adubada com $300 \mathrm{~kg}$ de N/ha/ano, permitiu o uso de elevadas taxas de lotação, proporcionando produção média de $88,3 \mathrm{~kg}$ de leite/ha/dia e rentabilidade média de US\$223,00/ha (CRUZ FILHO et al., 1996). Ademais, 
MAGALHÃES, J.A. et al. Produção de leite com vacas mestiças em capim-elefante. PUBVET, Londrina, V. 5, N. 35, Ed. 182, Art. 1226, 2011.

sob irrigação e adubação nitrogenada, essa gramínea tem apresentado elevado rendimento de matéria seca (RASSINI, 2004; MAGALHÃES et al., 2007).

De outro lado, a leucena (Leucaena leucocephala), uma leguminosa arbustiva e perene, vem sendo utilizada como alternativa de baixo custo na substituição parcial de rações comerciais para suplementação animal (URBANO et al., 2002; CARNEIRO et al., 2006; GARCÍA et al., 2008). No Havaí, produções de 9.700 litros de leite/ha foram obtidas em pastos de leucena + capim colonião (Panicum maximum), a uma lotação de 6 vacas/ha (JONES, 1979). Na Austrália, vacas Jersey em pastagens de "green panic" ( $P$. maximum) + leucena, produziram, sem suplementação de concentrado, 6.290 $\mathrm{kg}$ de leite/ha, durante nove meses (STOBBS, 1972, citado por JONES, 1979).

Este estudo teve por objetivo identificar fontes econômicas de suplementação alimentar para vacas leiteiras em pastagens de capim-elefante, submetidas à adubação e à irrigação de baixa vazão nos tabuleiros costeiros do Piauí.

\section{Material e métodos}

O trabalho foi conduzido em Parnaíba-PI, que apresenta um clima caracterizado como subúmido seco, megatérmico, com pequeno excedente hídrico e uma concentração de $32,6 \%$ da evapotranspiração potencial no último trimestre do ano (ANDRADE JUNIOR et al., 2005). A precipitação anual média é de $1.079 \mathrm{~mm}$ e o período chuvoso se concentra de janeiro a junho. A temperatura média anual é de $27^{\circ} \mathrm{C}$ e a umidade relativa média do ar é $75 \%$. O solo da área experimental foi classificado como Neossolo Quartzarênico Órtico Típico, de relevo plano (BASTOS et al., 2006).

$O$ delineamento experimental utilizado foi o inteiramente casualizado com três tratamentos e cinco repetições, onde cada animal representou uma repetição. Os tratamentos foram: $\mathrm{T} 1=$ vacas em lactação mantidas exclusivamente em pastagem de capim-elefante (Pennisetum purpureum cv. Napier); $\mathrm{T} 2=\mathrm{T} 1+$ banco de proteína de leucena e $\mathrm{T} 3=\mathrm{T} 1+$ ração concentrada, fornecida na quantidade de $1 \mathrm{~kg}$ para cada $3 \mathrm{~kg}$ de leite 
MAGALHÃES, J.A. et al. Produção de leite com vacas mestiças em capim-elefante. PUBVET, Londrina, V. 5, N. 35, Ed. 182, Art. 1226, 2011.

produzido acima de $5 \mathrm{~kg}$. A ração apresentava teores de proteína bruta entre 17 e $21 \%$ e era composta por milho (60\%), farelo de soja ( $37 \%)$, sal mineral $(2,5 \%)$ e calcário calcítico $(0,5 \%)$. Foram utilizadas 15 vacas do tipo Girolando em graus de sangue entre $1 / 2$ e $3 / 4$, que foram distribuídas nos tratamentos de acordo com a fase de lactação, grau de sangue e idade. As ordenhas eram realizadas pela manhã $(07: 00 \mathrm{~h})$ e à tarde $(15: 30 \mathrm{~h})$. As vacas pastejaram na área de capim-elefante, irrigada por um sistema de aspersão fixa de baixa vazão, onde as linhas laterais, de derivação e principais, são enterradas, havendo apenas a mudança dos aspersores entre os diversos tubos de subida, fixos e espalhados sobre a área de pastagem no espaçamento $12 \mathrm{~m} \times 12 \mathrm{~m}$ (DRUMOND; FERNANDES, 2001). As vacas do T2 tinham acesso ao banco de proteína de leucena pela manhã, durante três horas.

A área do capim-elefante foi adubada com $220 \mathrm{~kg}$ de nitrogênio e $135 \mathrm{~kg}$ de cloreto de potássio. Esta área foi subdividida por meio de cerca elétrica em piquetes com áreas variando entre 0,34 e 0,53 ha. Os períodos de ocupação variaram de um a três dias, seguidos de 30 a 45 dias de descanso para cada piquete.

A análise de custo foi realizada com base no custo operacional da produção de leite, realizado de acordo com a metodologia utilizada por Matsunaga et al. (1976), Leal et al. (1998) e Lopes e Magalhães (2005). Já, a análise de variância foi aplicada apenas às variáveis produção de leite por vaca/dia, produção de leite por vaca/lactação e período de lactação.

\section{Resultados e discussão}

A maior produção individual foi obtida dos animais do T3 $(11,11 \mathrm{~kg}$ de leite/vaca/dia), que foi significativamente superior $(P<0,05)$ à do $T 2(9,19 \mathrm{~kg}$ de leite/vaca/dia) e à do $T 1(8,54 \mathrm{~kg}$ de leite/vaca/dia). A produção de leite ( $\mathrm{kg}$ de leite/vaca/dia) dos animais do T2 foi também superior $(P<0,05)$ ao T1. A maior produção de leite por vaca/lactação foi obtida dos animais do T3 (3.594,08 kg de leite/vaca/lactação), que foi estatisticamente superior ( $P<$ $0,05)$ à do $T 2(2.740,15 \mathrm{~kg}$ de leite/vaca/lactação) e à do $T 1(2.520,36 \mathrm{~kg}$ de 
MAGALHÃES, J.A. et al. Produção de leite com vacas mestiças em capim-elefante. PUBVET, Londrina, V. 5, N. 35, Ed. 182, Art. 1226, 2011.

leite/vaca/lactação) (Tabela 1). A análise de variância não detectou diferenças entre os períodos de lactação, embora o maior período tenha sido registrado nas vacas do T3 (323,5 dias); seguido das do T2 $(298,17$ dias) e do T1 (295,13 dias) (Tabela 1). Esses dados estão próximos aos obtidos por Yamaguchi (1997), que utilizou capim-elefante e suplementação com 2 a 4 kg de concentrado. Entretanto, são inferiores aos descritos por Leal et al. (1998) e Derez (2001), obtidos de vacas mestiças mantidas exclusivamente em pastagem de capim elefante, que produziram, respectivamente, 12,9 e 11,9 $\mathrm{kg} / \mathrm{vaca} / \mathrm{dia}$.

A utilização de capim-elefante e leucena (T2) aumentou em 7,61\% $(9,19 \mathrm{~kg} / \mathrm{vaca} / \mathrm{dia})$ a produção de leite em relação aos animais mantidos exclusivamente em capim-elefante $(8,54 \mathrm{~kg} / \mathrm{vaca} / \mathrm{dia})$. Saucedo et al. (1980) obtiveram incrementos da ordem de $17 \%$ na produção de leite de vacas mestiças mantidas em pastagem de Cynodon plectostachyus adubadas com $200 \mathrm{~kg}$ de N/ha + banco de proteína de leucena. Hernández et al. (1994) encontraram uma produção média de $9,09 \mathrm{~kg}$ de leite/vaca/dia em vacas mantidas em capim-estrela (C. nlemfuensis), pangola (Digitaria decumbens), capim guiné ( $P$. maximum) e leucena. Macedo e Palma (1998) revelaram que a utilização de leucena aumentou 7,5 para $10 \mathrm{~kg}$ de leite de vacas mestiças no México. Em geral, vacas pastejando forrageiras tropicais produzem 8 a $10 \mathrm{~kg}$ de leite/dia (BENEDETTI, 2002). 
MAGALHÃES, J.A. et al. Produção de leite com vacas mestiças em capim-elefante. PUBVET, Londrina, V. 5, N. 35, Ed. 182, Art. 1226, 2011.

Tabela 1. Médias de produção de leite em capim-elefante irrigado e adubado, com e sem suplementação. Parnaíba, PI. 2004.

\begin{tabular}{lccc}
\hline Variáveis & $(\mathrm{T} 1)$ & $(\mathrm{T} 2)$ & $(\mathrm{T} 3)$ \\
\cline { 2 - 4 } & Capim-elefante & $\begin{array}{c}\text { Capim-elefante } \\
\text { l leucena }^{-}\end{array}$ & $\begin{array}{c}\text { Capim-elefante }+ \\
\text { ração }\end{array}$ \\
\hline $\begin{array}{l}\text { Período de lactação } \\
\text { (dias) }\end{array}$ & $295,13^{\mathrm{a}}$ & $298,17^{\mathrm{a}}$ & $323,5^{\mathrm{a}}$ \\
$\begin{array}{l}\text { Produção de leite } \\
\text { (kg/vaca/dia) }\end{array}$ & $8,54^{\mathrm{c}}$ & $9,19^{\mathrm{b}}$ & $11,11^{\mathrm{a}}$ \\
$\begin{array}{l}\text { Produção de leite } \\
\text { (kg/vaca/lactação) }\end{array}$ & $2.520,36^{\mathrm{b}}$ & $2.740,15^{\mathrm{b}}$ & $3.594,08^{\mathrm{a}}$ \\
$\begin{array}{l}\text { Produção de leite } \\
\text { (kg /ha/dia) }\end{array}$ & 29,89 & 32,16 & 38,88 \\
$\begin{array}{l}\text { Produção de leite } \\
\text { (kg/ha/ano) }\end{array}$ & $10.909,85$ & $11.738,4$ & $14.191,2$ \\
\hline $\begin{array}{l}\text { - Médias seguidas de letras diferentes nas linhas diferem entre si }(\mathrm{P}<0,05) \text { pelo teste de } \\
\text { Tukey. }\end{array}$
\end{tabular}

As médias de duração da lactação obtidas nos tratamentos, 295,13 dias (T1), 298,17 dias (T2) e 323,5 dias (T3), aproximaram-se dos resultados obtidos por Pereira et al. (2002), em vacas Girolandas na Amazônia, e são superiores às obtidas por Magalhães et al. (2003), em um sistema de produção de leite com gado mestiço mantido em pastagens adubadas e irrigadas, leucena e suplementação concentrada. Durães e Freitas (2000) reportaram que, nos últimos anos, a produção de leite e o período de lactação das vacas mestiças aumentaram consideravelmente, devido não somente à genética, mas também pelo melhoramento das condições nutricionais dos rebanhos, através do uso de tecnologias como suplementação na época seca e adubação e irrigação de pastagens.

Apesar da utilização de ração concentrada ter apresentado maior produtividade, seus custos superaram em 19 e $21 \%$ os tratamentos 2 e 1 , respectivamente, evidenciando, uma taxa de retorno de 0,45, contra 0,74 e 0,73 dos tratamentos 1 e 2 (Tabela 2 ). 
MAGALHÃES, J.A. et al. Produção de leite com vacas mestiças em capim-elefante. PUBVET, Londrina, V. 5, N. 35, Ed. 182, Art. 1226, 2011.

Tabela 2. Custo operacional de produção leite por hectare/ano em capimelefante com e sem suplementação. Parnaíba, PI. 2004.

\begin{tabular}{lccc}
\hline \multirow{2}{*}{ Variáveis } & $(\mathrm{T} 1)$ & $(\mathrm{T} 2)$ & $(\mathrm{T} 3)$ \\
\cline { 2 - 4 } & $\begin{array}{c}\text { Capim- } \\
\text { elefante }\end{array}$ & $\begin{array}{c}\text { Capim- } \\
\text { elefante }+ \\
\text { leucena }\end{array}$ & $\begin{array}{c}\text { Capim- } \\
\text { elefante }+ \\
\text { ração }\end{array}$ \\
\hline $\begin{array}{l}\text { Custo operacional (insumos, mão de } \\
\text { obra, transporte e energia) (R\$) }\end{array}$ & $3.461,22$ & $3.795,83$ & $5.499,62$ \\
$\begin{array}{l}\text { Reparo de máquinas e equipamentos } \\
\text { (5\% do custo operacional) (R\$) }\end{array}$ & 173,06 & 189,79 & 274,98 \\
Remuneração do capital de giro & & & \\
(15\% do custo operacional) (R\$) & 519,18 & 569,37 & 824,94 \\
Total (A) (R\$) & $4.326,53$ & $4.744,79$ & $6.874,53$ \\
Produção de leite por ha/ano (B) $(\mathrm{kg})$ & $10.909,85$ & $11.738,4$ & 14191,2 \\
Valor da produção(C) (R\$) & $7.636,89$ & $8.216,88$ & 9993,84 \\
Margem liquida (D=C-A) (R\$) & $3.310,36$ & $3.472,09$ & 3119,31 \\
Taxa de Retorno (E=D/A) & 0,74 & 0,73 & 0,45 \\
Custo do leite (F=A/B) (R\$) & 0,397 & 0,404 & 0,484 \\
\hline
\end{tabular}

Em geral, os resultados indicaram ser possível produzir leite em pastagens irrigadas e adubadas, com ou sem suplementação, ao custo entre $\mathrm{R} \$ 0,40$ e 0,50 o litro. A margem líquida anual da produção de leite é de $R \$$ $3.310,36$ para as vacas em lactação mantidas apenas com capim-elefante, $R \$$ 3.472,09 para as vacas em lactação mantidas em capim-elefante e leucena e $\mathrm{R} \$ 3.119,31$ para as vacas em lactação mantidas em capim-elefante e suplementação concentrada estratégica (Tabela 2). Esses resultados indicaram a possibilidade de obter uma renda mensal líquida de um salário mínimo por hectare, à época.

\section{Conclusão}

Na região Meio-Norte, a manutenção de vacas em lactação em pastagens cultivadas, adubadas e irrigadas, com e sem acesso a suplementação alimentar, possibilita a obtenção de índices de produtividade e econômicos satisfatórios, aproximando-se dos observados em outras regiões do país onde, tradicionalmente, a atividade leiteira é explorada. 


\section{Referências Bibliográficas}

ANDRADE JUNIOR, A.S. de; BASTOS, E.A.; BARROS, A.H.C.; SILVA, C.O. da; GOMES, A.A.N. Classificação climática e regionalização do semi-árido do Estado do Piauí sob cenários pluviométricos distintos. Revista Ciência Agronômica, v.36, n.2, p.143-151, 2005.

BASTOS, E. A.; ANDRADE JÚNIOR, A. S. de; RODRIGUES, B. H. N. Boletim agrometeorológico de 2006 para o município de Parnaíba, PI. Teresina: Embrapa MeioNorte, 2007. 38 p. (Embrapa Meio-Norte. Documentos, 155).

BENEDETTI, E. Produção de leite a pasto. Salvador, Secretaria da Agricultura, Irrigação e Reforma Agrária, 2002. 176p.

CARNEIRO, M.S.S.; SOUZA, P.Z.; PEIXOTO, M.J.A.; SALES, R. de O.; FEITOSA, J.V. Efeito do consórcio de capim-elefante com leucena na produção de forragem. Revista Caatinga, v.19, n. 1, p. 51-55, 2006.

CARO-COSTAS, R.; VICENT-CHANDLER, J. Milk production with all-grass rations on steep and intensively managed tropical pastures. Journal of Agriculture of the University of Puerto Rico, v.3, p. 251-258, 1969.

CRUZ FILHO, A.B. da; COSER, A.C.; PEREIRA, A.V. Produção de leite a pasto usando capim elefante: dados de transferência de tecnologia no norte Minas Gerais. In: REUNIÃO ANUAL DA SOCIEDADE BRASILEIRA DE ZOOTECNIA, 33., 1996, Fortaleza. Anais... Fortaleza: SBZ, 1996. p.200-203.

DEREZ, F. Produção de leite de vacas mestiças Holandês x Zebu em pastagem de capimelefante, manejada em sistema rotativo com e sem suplementação durante a época das chuvas. Revista Brasileira de Zootecnia, v.30, n.1, p.197-204, 2001.

DRUMOND, L.C.D.; FERNANDES, A.L.T. Irrigação por aspersão em malha. 1. ed. Uberaba, MG: Universidade de Uberaba, 2001. 84p.

DURÃES, M.C.; FREITAS, A.F. Cruzamento de raças aponta resultados eficazes. Revista Balde Branco, v.36, n.433, p.56-59, 2000.

GARCÍA, D. E.; WENCOMO, H. B.; GONZÁLEZ, M. E.; MEDINA, M.G.; COVA, L. J.A. Caracterización de diez cultivares forrajeros de Leucaena leucocephala basada en la composición química y la degradabilidad ruminal. Revista MVZ (Córdoba), v.13, n.2, p.12941303, 2008.

HeRnÁNDEZ, M.G.; SANCHEZ, C.; COlMENAREZ, J.; MONSALVE, M.R.; SieRraltA, R. Suplementación a corte de Leucaena leucocephala sobre producción de leche en vacas mestizas de doble propósito en el Valle de Aroa, Venezuela. Zootecnia Tropical, v.12, n.2, p.148-160, 1994.

JONES, R.J. The value of Leucaena leucocephala as a feed for ruminants in the tropics. World Animal Review, v.31, p.13-23, 1979.

LEAL, J.A.; FROTA, A.B.; NASCIMENTO, H.T.S. do. Produção de leite em pastagem de capimelefante e Panicum maximum, no Piauí: custos operacionais. In: REUNIÃO ANUAL DA SOCIEDADE BRASILEIRA DE ZOOTECNIA, 35., 1998, Botucatu. Anais... Botucatu: SBZ, 1998. 3p. (CD-ROM). 
LIMA, M.L.P.; PEDREIRA, C.G.S.; ROSSETO, F.A.A.; BERCHIELLI, T.T.; LEME, P.R.; NOGUEIRA, J.R. Produção de leite de vacas mestiças mantidas em pastagens de capim-elefante e capimtanzânia em São Paulo. Boletim de Indústria Animal, v.63, p.217-226, 2006.

LOPES, M.A.; MAGALHÃES, G.P. Análise da rentabilidade da terminação de bovinos de corte em condição de confinamento: um estudo de caso. Arquivo Brasileiro de Medicina Veterinária e Zootecnia, v.57, n.3, p 374-379, 2005.

MACEDO, R.; PALMA, J.M. Evaluación productiva y econômica de bancos de Leucaena leucocephala en Colima, Mexico. Revista de la Faculdad de Agronomia (LUZ), v.15, p.460471, 1998.

MAGALHÃES, J.A.; LOPES, E.A.; RODRIGUES, B.H.N.; ARAÚJO NETTO, R.B. de A.; COSTA, N. de L.; LOPES NETO, L.; BEZERRA, E.E.A. Eficiência técnica de um sistema de produção com gado mestiço para as bacias leiteiras dos estados do Piauí e Maranhão. Agropecuária Catarinense, v. 16, n. 3, p. 30-62, 2003.

MAGALHÃES, J.A.; RODRIGUES, B.H.N.; CARNEIRO, M.S.S.; COSTA, N. de L.; ARAÚJO FILHO, J.M. de. Efeito do nitrogênio e da idade de corte sobre a produção de cultivares de capimelefante. Pasturas Tropicales, v.28, p.68-75, 2007.

MATSUNAGA, M.; BEMELMANS, P.F.; TOLEDO, P.E.N. de; DULLEY, R.D.; OKAWA, H.; PEROSO, I.A. Metodologia de custo de produção utilizado pelo IEA. Agricultura em São Paulo, v.23, n.1, p.123-139, 1976.

PEREIRA, R.G. de A.; SILVA NETTO, F.G.; COSTA, N. de L.; TOWNSEND, C.R.; MAGALHÃES, J.A. Avaliação da produtividade de um rebanho de vacas girolando em Rondônia In: SIMPÓSIO LATINO-AMERICANO SOBRE INVESTIGAÇÃO E EXTENSÃO EM PESQUISA AGROPECUÁRIA, 5., 2002, Florianópolis. Anais... Florianópolis: SBSB/EPAGRI/EMBRAPA, 2002. 1-6.

RASSINI, J. B. Período de estacionalidade de produção de pastagens irrigadas. Pesquisa Agropecuária Brasileira, v.39, n.8, p.821-825, 2004.

SAUCEDO, G.; ALVAREZ, F.J.; JIMENEZ, N.; ARRIAGA, A. Leucaena leucocephala as a supplement for milk production on tropical pastures with dual purpose cattle. Tropical Animal Production, v.5, n.1, p.38-42, 1980.

URBANO, D.; DÁVILA, C.; SAAVEDRA, S.; RIVAS, N.; MORANTES, W. Impacto económico sobre la produccíon de leche en un sistema de pastoreo con asociaciones gramíneasleguminosas arbóreas en el Sur del Lago de Maracaibo, Venezuela. Archivos Latinoamericanos de Producción Animal, v.10, n.2, p.102-109, 2002.

YAMAGUCHI, L.C.T. Retorno do capital imobilizado na produção de leite em regime de pastejo rotativo de capim-elefante (Pennisetum purpureum, Schum). In: Capim-elefante: produção e utilização. Brasília: Embrapa-SPI/Juiz de Fora: Embrapa-CNPGL. p.209-219, 1997. 